\title{
The ethics of clinical trials
}

\author{
J K Wing MRC Social Psychiatry Unit, Institute of Psychiatry, London
}

In this commentary on the preceding paper (pages 168-173), Professor Wing, Director of the MRC Social Psychiatry Unit at the Institute of Psychiatry in London, pursues further the thesis that it is sometimes unethical not to conduct clinical trials. He sets the problem in the framework of the whole of clinical activity and not only that of clinical trials. At the heart of it all is the doctor's own responsibility and right to judge and to act according to conscience. And this must be preserved at all costs no matter what 'society' attempts to dictate.

The main postulate of Professor Helmchen and Professor Müller-Oerlinghausen is that it can sometimes be unethical not to conduct clinical trials; sometimes unethical not to withhold information from patients; sometimes unethical not to act as though social interests were more important than those of the individual. They are right. The essence of the problem, which is highlighted by the new West German law requiring all drugs to be adequately tested, is under what circumstances is it ethical or unethical to behave in these ways?

\section{The moral problems of clinical activity}

Before attempting to answer this question it is important to recognize that clinical trials are only a tiny fraction of clinical activity and that the moral problems involved are not changed in any way by reason of the intention to carry out an experiment. If anything, they are made simpler. For present purposes we may take 'clinical practice' to include not only medicine but psychology and social work as well. The following considerations are relevant.

First, it is impossible for the clinician to tell the patient (or client) everything that is in his mind. He must select. Second, the patient can only rarely be as well informed as the clinician. Even when, in exceptional cases, the patient is himself a doctor, has taken a second opinion, looked up the textbooks, consulted the original papers, obtained the best statistics as to cure rates and side effects and so on, he will usually still need advice as to the best course of action. Most patients, of course, do not wish to go to such lengths. They simply want advice. Third, even if it were feasible to spend a very long time with each patient, attempting to inform him of all the ins and outs influencing some particular recommendation it would often be undesirable to do so on ethical grounds, since the patient might well receive the impression that the clinician was unwilling to take responsibility and therefore come to doubt the value of the advice. Finally there is the difficult question of gauging how far the patient can understand an explanation of why a particular treatment or course of action is recommended rather than all the various alternatives available to the clinician. In the last resort, the matter is one of whether the patient can trust the clinician or not.

\section{Freedom of doctors to act according to conscience}

A recent document on 'Confidentiality of information about psychiatric patients collected by medical information systems' adopted by the Royal College of Psychiatrists makes a useful distinction between 'the individual doctor's own decision in any given case, which must be his own moral responsibility, and a set of ethical guidelines which may be laid down by a professional or lay body in order to help him take the decision. In the last resort, the trust of the public, individually and collectively, in the medical profession will depend upon the cumulative effect of a myriad decisions of the first kind. A doctor must always be free to follow his conscience.'

Hence, no matter what 'society' thinks about the necessity or otherwise for clinical trials, the freedom of individual clinicians to decide whether or not to allow his own patients to be included in a trial, and whether or not 'fully informed consent' is feasible or necessary, must be preserved at all costs. We must be clear, however, that we are here dealing with individual and not group ethics. The decision must be made in precisely the same way as it would have been if no clinical trial were involved. One clinician may believe that the value of the treatment under test has already been sufficiently demonstrated and will therefore refuse to expose his patient to the risk of its withdrawal in a clinical trial. This decision must be respected but it cannot be imposed on other clinicians who think differently. Clearly, as Professors Helmchen and MüllerOerlinghausen point out, this will introduce biases, but a variety of designs is available to take care of this problem and, in any case, an epidemiological approach always needs to be adopted in order to 
determine the limits within which the results can be generalized (Leff, 1973).

\section{The principle of conscience applied}

This principle should also be applied to the problem of whether or not to obtain 'informed consent'. This issue is particularly important in the kind of trial that Professors Helmchen and Müller-Oerlinghausen do not consider. In this case a treatment becomes generally adopted (often, though not always, because of its proven efficacy in ameliorating some acute condition) and is continued after the patient has become well because it is thought to prevent further relapses, even though this has not been proved. It is precisely in such situations that the dangers of adverse reactions developing after long periods of administration are most apparent.

This is the problem, for example, with long-term maintenance medication with the phenothiazines. Is it justifiable to inform a patient, after he has been taking the medication for a long time, that it is uncertain whether it is effective and uncertain whether it is dangerous? The result might very well be to destroy his trust in a form of preventive medication that might be both effective and safe. Again, the ethical problem can only be resolved by the clinician, in the light of his scientific knowledge and his acquaintance with the individual patient. In a recent trial of fluphenazine decanoate, the clinicians concerned decided that it was ethically correct to include certain of their patients without obtaining their 'informed consent' (Hirsch, Gaind, Rohde, Stevens and Wing, 1973). Another clinician objected to this trial (and indeed to all trials) on 'ethical' grounds (Sargant, 1975) but he was assuming that his personal faith in the drug's efficacy and safety ought to have been shared by the clinicians who allowed their patients to take part in the trial. The fact that his faith was not so shared is not a matter for ethics at all but for rational argument about evidence.

This particular trial did show a superior preventative effect of drug over placebo in the short term and, taken together with other scientific data about the interaction between social and pharmacological treatments (Wing, Leff and Hirsch, 1973), it allows a much better informed decision to be made by clinicians in future. It does not, however, answer the question as to whether dangerous side effects might develop in the longer term and thus some ethical doubt remains.

\section{Ethical guidelines for clinical trials}

At this point we can turn to the other kind of moral problem distinguished in the Royal College of Psychiatrists' document, that of ethical guidelines. The statement by the Medical Research Council (1963) concerning the limits within which clinical trials should be conducted has been widely accepted and if individual clinicians step outside these limits they are taking a grave responsibility. The statement does, of course, leave plenty of scope for variation between specific projects. A further safeguard has been the establishment of ethical committees whose duty it is to consider the details of any particular experiment in order to determine whether it is ethically sound. Again, an individual clinician would ignore such counsel at his own risk. The role of such statements and such committees is not only to indicate the ethical limits within which clinicians ought to stay when undertaking experiments, it is also to support the ethical case for undertaking experiments when the balance of knowledge as between the possibly beneficial and possibly harmful effects of a treatment is undecided.

There is a further safeguard at governmental level since it is possible to set up legal sanctions against the introduction to general clinical use of potentially dangerous forms of treatment before they have been adequately tested. Government committees also advise on the limits within which certain drugs should be used. We do not, for example, allow doctors to prescribe heroin exactly as they please.

\section{Summary}

In summary, the discussion by Professors Helmchen and Müller-Oerlinghausen of the morality of clinical trials has emphasized a point that is frequently overlooked. It is as essential to consider those situations in which it might be unethical not to conduct a trial as it is to be concerned about the ways in which trials might restrict the rights of the individuals taking part in them. They and $I$ have dealt mainly with the first of these two issues because it has been relatively neglected. The second is, of course, equally important and has rightly received much attention. Both matters deserve further public discussion.

\section{References}

Hirsch, S R, Gaind, R, Rohde, P D, Stevens, B C, and Wing, J K (1973). Outpatient maintenance of chronic schizophrenic patients with long-acting fluphenazine. British Medical fournal, 1, 633-7.

Leff, J (1973). Influence of selection of patients on results of clinical trials. British Medical fournal, 4, 156-158.

Medical Research Council (1963). Responsibility in investigations on human subjects. Report of the Medical Research Council, 1962-63. Cmnd 2382. London: HMSO.

Sargant, W (1975). Should patients be 'tortured' in the name of progress? The Times, 29 August, 1975.

Wing, J K, Leff, J, and Hirsch, S H (1973). Preventive treatment of schizophrenia. In Psychopathology and Psychopharmacology. Eds. J Cole, A M Freedman, A J Friedhoff. Baltimore. Johns Hopkins University Press. 